\title{
Selling a dream? Information asymmetry and integrity within promotional literature for popular music courses
}

\begin{abstract}
Providers of higher education have a legal responsibility to provide accurate information to students. In an increasingly marketized sector, however, promotional imperatives place pressure on providers to 'sell' degrees to students. Given the indeterminate nature of popular music careers, not to mention the 'intangible product' that is Higher Education, the implicit or explicit indication of an assurance of career success upon completion of the degree could be regarded as being overstated.

This article brings to bear a qualitative linguistic analysis of the terms and constructed meanings implied within promotional literature across a range of performance-based popular music degrees. It suggests that language in this context functions in a performative sense and can perpetuate questionable conceptions of popular music careers and the efficacy of degree courses. The article concludes with suggestions of improvements that might be made across the sector in the promotion of popular music degree courses.
\end{abstract}

\section{Key words}

Careers, courses, higher education, language, promotional, popular music, marketization, music industries

\section{Introduction}

The motivation for undertaking this investigation stems from the author's wider research into the efficacy of UK popular music performance-based degrees in helping students to establish sustainable, successful music careers (Hall 2017). Performance-based Higher Popular Music Education (HPME) degrees are a relatively nascent but fast-growing part of UK creative arts higher education provision, bringing in applicants who may otherwise not have considered higher education, and supporting an agenda of widening participation (Bennett 2015; Parkinson 2017). Moreover, the attendant focus on employability, skills and entrepreneurship common to many popular music degrees is a good fit (at least ideologically) for an increasing narrative towards graduate employability and concepts of value for money (John and Fanghanel 2015; Parkinson 2017). However, while there have been various attempts to map the creative industries (DCMS 1998; Bakhshi et al. 2012), the notion of a defined popular music industry remains opaque (Williamson and Cloonan 2007; Hewison 2014). Furthermore, individuals working professionally in the creative arts sector often report low earnings and job insecurity regardless of qualification level (Menger 2006; McGuigan 2010; Hall 2017). In view of this, the investigation aimed to gain an understanding of the ways in which HPME degrees were 
'pitched' to students. I undertook analysis to assess how certain linguistic choices within promotional literature were being used and combined to imply specific meaning or suggestion of career potential.

\section{The marketization of UK higher education}

The creative arts sector is home to one of the UK's biggest export industries, with the music industries contributing $£ 4$.1bn annually to the UK economy and supporting some 119,020 fulltime equivalent jobs (UK Music 2016). By way of comparison, the UK film industry supports around 80,000 jobs and is worth an estimated £1.4bn (BFI 2017). Growth in the creative industries has been paralleled by the rise in the number of higher education degree programmes designed to serve them (Ball et al. 2010; Parkinson 2017). Data from the Higher Education Statistics Agency (HESA) show the number of first degree qualifications awarded across all UK higher education providers in the field of Creative Arts and Design was 14,633 in 1994 1995 (HESA 1996) compared with 144,595 in 2011 - 2012 (HESA 2013): an increase of nearly 1,000\%. Currently, the Universities and Colleges Admissions Service (UCAS) lists some 1,948 full-time degree-level programmes for music, of which 514 across 55 providers are popular music-based. Recent reports in the UK media, however, have reported a downturn in the number of young people entering HE generally (Pells 2017).

Sanigar (2013) observes that in an increasingly marketized sector, education can no longer be expected merely to sell itself. As the result of a move towards marketization, she observes 'an increased focus on language with text producers manipulating its evaluative resources as a means to a promotional end' (Sanigar 2013: 85). Therefore, the way performance-based HPME degrees are promoted is an important consideration as the promotional efforts of the respective Higher Education Providers (HEPs) (via websites and other materials) will, for many, represent the first encounter with their potential choice of programme and HEP. Use of language is also important with regard to what Sewell (1992) refers to as deep structural schemas, whereby constructions of language can sustain and proliferate unquestioned assumptions of reality. In this sense, language could be said to have the capacity to crystallise understanding.

Given the indeterminate nature of careers within the popular music industries (PMI), not to mention the 'intangible product' that is HE (Morrish and Saunston 2013: 61), promotional material that would either implicitly or explicitly indicate an assurance of success or career upon completion of the degree could be regarded as overstated. HEPs will of course want to advertise and present degree programmes in the best possible light and students will doubtless be viewing and evaluating a number of different options. Nonetheless, responsibility falls to all HEPs to present accurate and reliable information to prospective students as stipulated with the Quality Assurance Agency Quality Code Part C - Information about higher education provision (QAA 2012).

\section{Reductive narratives of the market}

Education environments do not necessarily dispel incorrect conceptions of careers and success (Ford 2010; Cloonan 2005). Ford (2010) notes that students can have unrealistic career aspirations and be seduced by individual examples of alumni success stories. These examples serve as role models to students, but those students lack a full understanding of the nonperformance aspects that constitute a significant portion of that individual's career. This, Ford notes, is compounded by 'students holding incorrect assumptions about 'the world of work' and its freelance, protean nature' (Ford 2010: 43). 
Carey and Lebler (2012) argue that HEPs tend to proliferate a view that musical careers conform to a sort of meritocracy, whereby the best performers will likely have the most successful careers. Cloonan (2005) refers to a 'hype' that exists which suggests the singular role of a popular music degree is to produce 'pop stars' and suggests that HEPs do little to diffuse the idea that popular music degrees are not 'automatic paths into the industries' (Cloonan 2005: 85). This has led to a pedagogic preoccupation with instrumental and performance-based activities which arguably leave students ill equipped for the professional industries in which they seek to establish careers (Hughes et al. 2016). In reality, career success in the new music industries (Hughes et al. 2016) is a far more nuanced process and is a product of multiple creativities as well as integration of artistic and entrepreneurial qualities. In support of this, Hewison (2014) and Bennett (2015) conceptualize the new music industries as an ecosystem, acknowledging a structural shift 'in which people may play different roles at different times or in different aspects of their career' (Hewison 2014: 421).

Despite such developments in understanding, reductive concepts of the music industry prevail due to structures (of language, pedagogy, curricula, for example) that are continuously reaffirmed rather than challenged. These structures exist within a 'wide range of institutional spheres, practices, and discourses' (Sewell 1992: 22). These unconscious, deep structures can often lie within the cultural language of a particular social group as 'taken-for-granted mental assumptions or modes of procedure that actors apply without being aware that they are applying them' (Sewell 1992: 22). Sewell identifies this as linguistic structure and suggests such unconscious structures sit as a foundation from which is derived 'rhetoric, narrative, metaphor and logic' (Sewell 1992: 24). To be able to see past these linguistic structures requires prospective students to be 'knowledgeable agents'. This requires an individual to operate with a degree of cognizance of the professional environment and its structures. However, in practice, undergraduate students will often be limited in experience and accurate cognizance of the realities of the industries in which they seek employment - thereby leading to information asymmetry (Hall 2017).

\section{Method}

The focus of the investigation was to determine whether examples of language used in promotional materials could be regarded as overstatement. Given the indeterminate nature of careers within the popular music industries, promotional material that would either implicitly or explicitly indicate an assurance of success or career upon completion of the degree programme was regarded as overstated. To that end, degree programme descriptions or overview statements from 27 performance-based popular music degree programmes, spread across 25 HEPs in the UK, were viewed from the top level or home section of each programme's webpage. HEPs from both the alternative provider and the university sector were represented. Programmes were identified by conducting a search though the UCAS (Universities and Colleges Admissions Service) website which offers a comprehensive database of UK higher and further education programmes.

Initial data was separated into two categories using a simple interpretive framework: promotional literature that was interpreted as using overstated language (as outlined above), and promotional literature that used mainly factual, descriptive language about the degree and did not allude to success or career. The interpretive framework consisted of a textual analytical process whereby terms or phrases were highlighted if they were suggestive (either explicitly or implicitly) of a promise of success, should an individual undertake that degree programme. A simple colour coding method was utilized (see table 1): 


$\begin{array}{ll}\text { Grey } & \text { References to employment and career longevity } \\ \text { Blue } & \text { References to 'music industry' } \\ \text { Yellow } & \text { Use of the word 'career' } \\ \text { Green } & \text { Use of the word 'professional' }\end{array}$

Table 1: Colour coding interpretive framework.

This was not an exhaustive study, and not all HEPs offering degrees in popular music were viewed, only those with an emphasis on performance. Neither was this a full analysis of all material relating to the degree, rather just the initial or 'first level' of promotional material which would be likely to form part of a student's first encounter. It does, however, provide a useful snapshot of a significant percentage of HEPs and degrees relevant to the research question. Table 2 shows the colour coding of the various extracts from the overstated language data set.

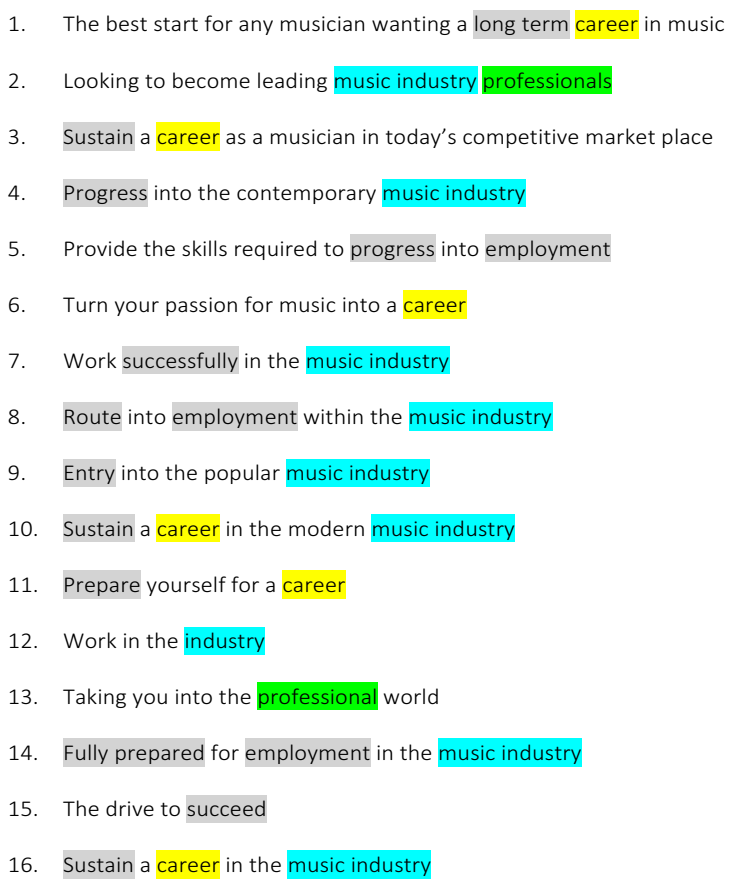



17. Making it as a pop-musician
18. Sustain a career as a working musician
19. Get a head-start in the industry
20. The confidence and contacts to succeed
21. Preparing you for success in the music industry and beyond
22. The programme equips students with the full 360-degree skillset
23. Work as freelance musicians in the popular music industry
24. Professional skills for successful, sustainable music careers
25. Professional skills for a career in today's music and entertainment industry
26. Turn your musical passions into a career
27. Kick-start your professional musical career
28. Musicianship to a level appropriate for a career in the music industry
29. Ensure your career is on track for success in today's marketplace
30. Your route into the industry
31. Prepares you for a career in the music industry
32. Assist you in becoming a professional musician

Table 2: Colour coding of 'overstated language' extracts.

As a useful comparison, table 3 shows the colour coding of the various extracts from the nonoverstated language data set.

1. Learn how to stand out as a performer, engage your audience and respond to other musicians

2. Develop your musicianship skills, broaden your knowledge and expertise in a wide range of musical genres

3. Explore performance, composition, production and music technology with a specific focus on popular music.

4. Study and perform a diverse range of styles, and enhance the future of your sound by connecting with other art forms.

5. The opportunity to develop a unique and contemporary popular music practice.

6. Expand your skills, whether it's playing in bands or writing, performing music for film, theatre or multimedia

7. Graduates leave not only with a wealth of experience and transferable skills, but also a professional portfolio to showcase their work

8. Study on an industry-focused program in an inspiring art school environment.

9. Explore modern song writing, performance, studio production and critical musicology

10. Compose, perform, record, listen to and write about popular music to develop your musical and academic skills.

11. Designed for applicants with an interest and experience in composition and performance

12. Develop a breadth of skills to pursue a portfolio career in the Music Industries

13. Preparing you to creatively respond within a range of professional situations

14. Tailor the degree to your interests and career aspirations 


\section{Visual representation}

To provide a visual dimension to the data, a graphical representation was produced to allow a snapshot overview of the key emphases provided within the promotional literature. The two data sets were inputted separately into an online word cloud generator (www.wordle.net) producing a graphical representation whereby words are attributed a larger font size proportional to their frequency of occurrence. In order to bring parity and mitigate the differential in the word counts of the two data sets, a one-hundred maximum word filter was applied in both cases (limiting the visual representation to the one hundred most commonly occurring words). Furthermore, in order to focus more specifically on the most salient words in each data set, a further filter of a maximum five words was applied. This allowed for a clear and unambiguous visual representation of the most commonly occurring words for both data sets (word cloud images are included below in figures 2 and 4 ).

\section{Corpus linguistic analysis}

An additional comparative stage of analysis was conducted between the two data sets using the AntConc analytical software. The excerpts from the respective programme web pages were combined to create a 2,375-word corpus on which an analysis could be conducted. This allowed for a detailed comparative search between the two data sets using various tools within the software.

\section{Findings}

Of the 25 HEPs reviewed, eight (thirty-two per cent) avoided use of overstated language, and seventeen (sixty-eight per cent) made use of such language in their front page or programme descriptors.

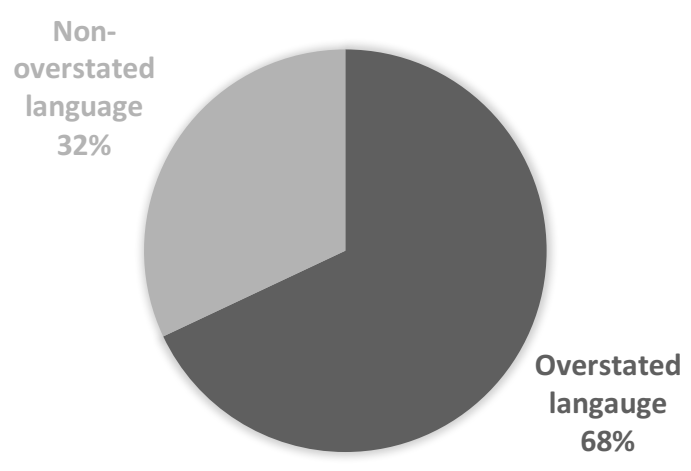

Figure 1: Proportion of HEPs utilising overstated language in promotional literature.

What follows is analysis of some of the linguistic examples mined from those HEP webpages interpreted as containing examples of overstated language. 


\section{Industry as proximate}

The music industries are referred to by each HEP in the singular form rather than the plural. Consequently HEPs, although perhaps unintentionally, remain complicit in the perpetuation of the illusion of a singular, definable popular music industry. Moreover, the language in use portrays a sense of nearness to the industry from which students are but a step away. Degree programmes are then characterized as the potential conduits through which a student can transition from study to a professional career.

\section{Ex. 1 - 'Taking you into the professional world' (HEP 11) \\ Ex. 2 - 'Progress into the contemporary music industry' (HEP 2) \\ Ex. 3 - 'Route into employment within the music industry' (HEP 5)}

In example one, co-occurrence of the words 'professional' and 'world' imply the PMI are a discrete and definable entity. Furthermore, a strong indication is given that the completion of that HEP's degree will 'take you' or otherwise lead the student into professional employment. Use of the verb 'progress' in example two implies that a series of distinctive steps exist by which an individual can make measured movement towards the goal of a professional career. Example three supports this notion using different terms, but nevertheless suggesting a professional career in the PMI is the function of an upward trajectory, with the degree acting as the progressing agent. Clearly, not everyone will interpret such phrases in as suggestive a way as is outlined here. However, it is plausible that when influenced by a strong pull towards a professional career, individuals may infer from these examples that professional careers are readily available and that a clear and definitive 'route' towards employment exists.

\section{The imperative of study}

Within the narrative of a singular and proximate popular music industry, it is far easier to assert the vocational value that popular music study offers. In some instances, a clear assertion of the vocational value of study is made in the promotion language.

Ex. 1 - 'Qualify quickly and get a head-start in the industry' (HEP 16)

Ex. 2 - 'Kick-start your professional musical career' (HEP 23)

Ex. 3 - 'The best start for any musician wanting a long-term career in music' (HEP 1)

Ex. 4 - 'Ensure your career is on track for success in today's marketplace' (HEP 24)

Both a sense of urgency and imperative are implied with the co-occurrence of 'qualify quickly' and 'head-start' within the same sentence. The suggestion here is that a professional music career is something for which an individual can qualify (much in the same way an individual might qualify for a commercial driver's license) and that it is possible to gain a higher footing within the industry as a result of completing that HEP's degree.

The opacity of the imagery presented by the term 'kick-start' is particularly noteworthy. It is implied that the student possesses the necessary capabilities to sustain a professional career, but requires some form of catalyst, provided by the respective HEP's degree. There is also an immediacy to the term, similar to that of 'qualify quickly', which is suggestive of a fast and linear process to career development. The assertion in example three that a popular music 
performance degree represents the 'best start' is a rather arbitrary statement. The link to a notion of sustainability (by use of the phrase 'long-term career') is evocative in that it makes a specifically future-bound promise regarding career longevity: an ambitious promise given the volatile nature of the PMI.

A level of certainty with regard to a professional career is suggested in example four by subtly referring to a student's career as if it were already something begun, and that the degree in question would ensure the career would remain on the right 'track'. Furthermore, use of the word 'track' here implies a distinct and observable trajectory through employment. The language of business is brought into the lexicon here, with reference to a marketplace. The cooccurrence of marketplace and the qualifying prefix 'today's' suggests that the PMI are an evolving entity for which the HEP's degree is well placed to prepare a student - perhaps where other degrees may not. In practice, such phrases might better reflect the reality of careers in teaching or engineering than careers in the creative industries. They appear to present a simplified interpretation of typical career trajectories for those working within the PMI, which might influence a student's decision to pursue HPME.

\section{Vocational value}

In a number of cases, links were implied between the acquisition of the knowledge and skills being promised in the degree, and subsequent 'success' or the ability to 'sustain a career'.

Ex. 1 - 'Provide the skills required to progress into employment' (HEP 2)

Ex. 2 - 'Professional skills for successful, sustainable music careers' (HEP 21)

Ex. 3 - 'Professional skills for a career in today's music and entertainment industry' (HEP 22)

The use of the definite article in the first example could be construed to infer a specific and definitive set of skills that act as a prerequisite for a career, as might be stipulated by a PSRB (professional, statutory and regulatory body) for the sector. However, because no such external professional body exists within the field of popular music, it is not clear who defines the skills considered a requirement here. If the HEP in question does not possess a list of such required skills, then the statement would lack a substantive underpinning. The second and third examples avoid the use of the definite article when referring to the notion of 'skills' but nevertheless suggest that the ability to sustain a career is a function of possessing a specific skill set.

It is worth noting here that the Quality Assurance Agency (QAA) - an independent body responsible for the safeguarding of standards in UK higher education - publishes subjectspecific benchmark 'statements' to which UK providers are expected to refer when designing degree programmes. However, these benchmarks are written with a broad scope intended to cover some 44 potential specialisms existing under the general banner of music (only three of which specifically mention popular music) and are intended only to 'capture the basic attributes expected of a Music student' (QAA 2016: 5). Furthermore, they are written with a view to maintaining academic standards rather than seeking to ensure professional relevance - though the two need not be mutually exclusive.

The Destinations of Leavers from Higher Education (DHLE) survey provides statistics around graduate employment in a general sense. The 2016/17 results (the most recent available at the 
time of writing) list full-time employment statistics 6-months after graduating for creative arts and design graduates as $49.7 \%$. By way of comparison, medicine and dentistry was $93.6 \%$ (HESA 2019). Individual degree programmes, however, tend to list their own statistics relating to employment, some of which can appear to show comparatively high success rates. For example, one HPMPE provider cites an employment success rate on their website as $86 \%$, of which $83 \%$ were employed within the music and creative industries. However, no detail is provided on precisely what constitutes the music and creative industries and how broadly those are interpreted in this statistic. Therefore, without a transparent methodology as to how such statistics are derived, the levels of implied graduate success, as well as the clear links implied within the above three promotional excerpts, may be misleading.

\section{Terms of ambiguity}

Within the promotional language there were a number of terms whose meanings were rather ambiguous. Whilst many of the previous examples had an air of factual specificity to them, other terms in use seemed inflated.

Ex. 1 - 'Looking to become leading music industry professionals' (HEP 1)

Ex. 2 - 'Turn your passion for music into a career' (HEP 5)

Ex. 3 - 'Making it as a pop-musician' (HEP 16)

At first glance, example one does not appear problematic, and would not seem out of place within promotional literature for other disciplines. It is not difficult to imagine what an individual might need to do to become a leading industry professional within architecture, for example. However, the term 'leading professional' becomes problematic when applied within the context of the PMI. The disparate nature of the various sectors of the PMI, and the decidedly un-meritocratic nature of popular music careers make it hard to imagine what a 'leading professional' might look like, and harder still to imagine how an individual might set about becoming one.

The turn of phrase in example two implies a form of educational alchemy whereby the student provides the passion, whatever form that may take, and the HEP provides the catalyst by which that student's passion is transformed into a musical career. This is a markedly different view compared to the instrumentalist view of careers as a function of skill set. In many respects, the colloquial or informal nature of the language belies the importance of the decision students make when choosing not only a HEP within which to study, but also the life choice of a future career.

Finally, example three ('making it as a pop-musician') includes perhaps the most questionable of terms from all the promotional materials. It is a deliberate use of colloquial language designed to illicit attention from prospective students. In the vernacular of popular culture, to 'make it' is to achieve a high level of financial success and celebrity status, but the reality is that only a small elite realise such an aspiration. To use such a frame of reference within promotional literature seems misguided at best, as it places value on nothing except high levels of commercial success, thereby devaluing more modest forms of career 'success'. 


\section{Contrasts between the two data sets}

Comparison between the two data sets (the overstated and the non-overstated) on various word searches highlight some of the more salient differences in the two promotional approaches. For example, the word 'career' appears 15 times in the overstated data set compared with just three times in the non-overstated data set. Clearly, emphasis on the vocational value of the degree in enabling a student to establish a career is stronger in the overstated than in the non-overstated data set. Few specific references to the degree leading to a career are given in the nonoverstated data set. A similar result is derived when changing the word search from 'career' to 'work' (whereby the overstated data set mentions this term a total of fourteen times, versus just four times in the non-overstated data set). Broadening the word search to include two cooccurring words 'professional' and 'skill' again yields a similar differential between the two data sets. The overstated data set makes mention of both professional and skill a total of 27 times as opposed to thirteen times in the non-overstated data set. Searching for the word 'industry' reveals 22 occurrences in the overstated data set, and only five in the non-overstated data set. Accordingly, differences in the two promotional approaches are stark.

\begin{tabular}{c|cc}
\hline WORD SEARCH TERM & OVERSTATED OCCURRENCE & NON-OVERSTATED OCCURRENCE \\
\hline CAREER & 15 & 3 \\
WORK & 14 & 4 \\
PROFESSIONAL + SKILL & 27 & 13 \\
INDUSTRY & 22 & 5 \\
\hline
\end{tabular}

Table 4: Word search results between the two data sets.

\section{Visual representation}

It is helpful, in the case of the corpus linguistic data, to be able to view the frequency of word occurrence weighted in graphical form. The following figures provide visual representation of the most commonly occurring words within the overstated promotional literature - whereby the most commonly occurring words are attributed a larger font proportional to frequency. In this way, it is easy to gain a clear view of the language landscape across the various HEPs.

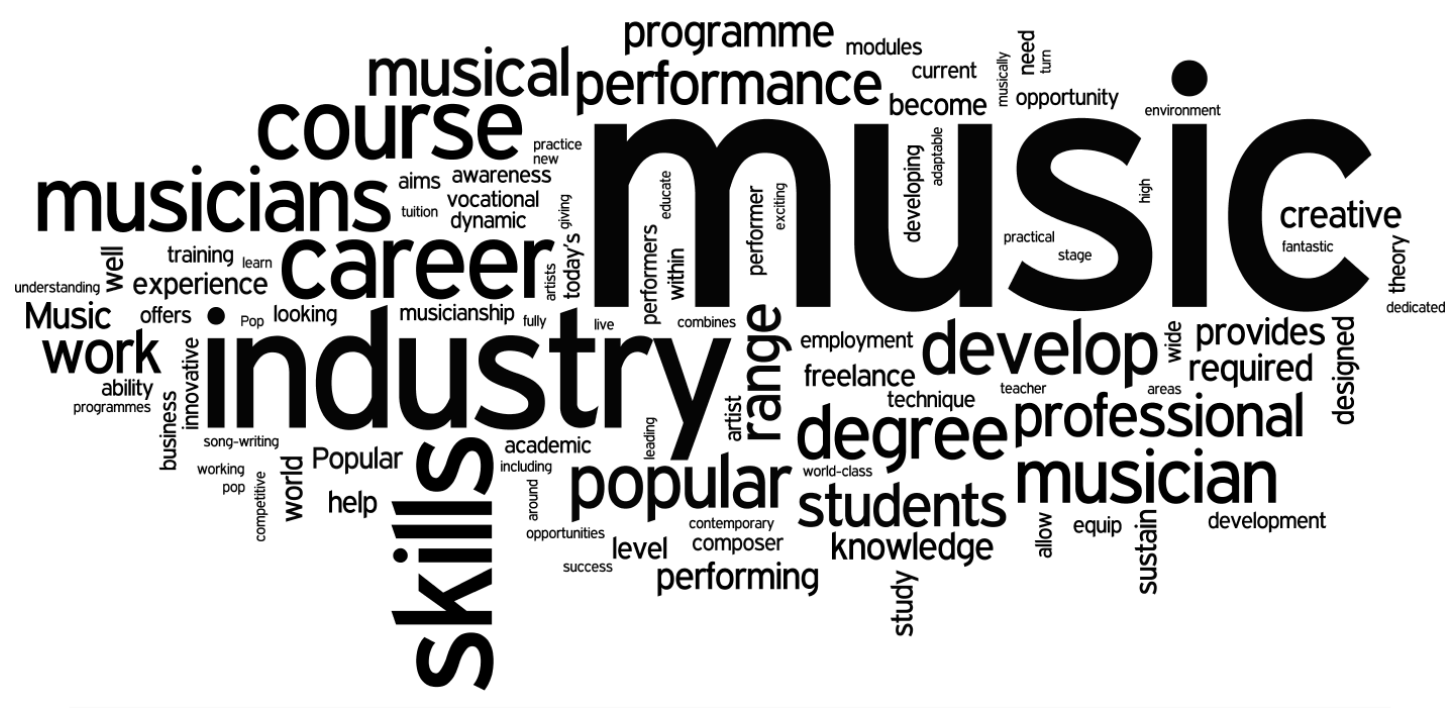


Figure 2: Overstated promotional language extracts (100-word maximum filter applied).

The image above details in graphical form the most commonly occurring words in the promotional extracts from programme web pages of HEPs regarded as using overstated language. A filter has been applied so that only the 100 most commonly occurring words are represented (the software automatically filters out redundant pronouns and conjunctions such as 'it' or 'and'). By applying a more severe filter of only five words, the image can focus in on the key most words utilized:

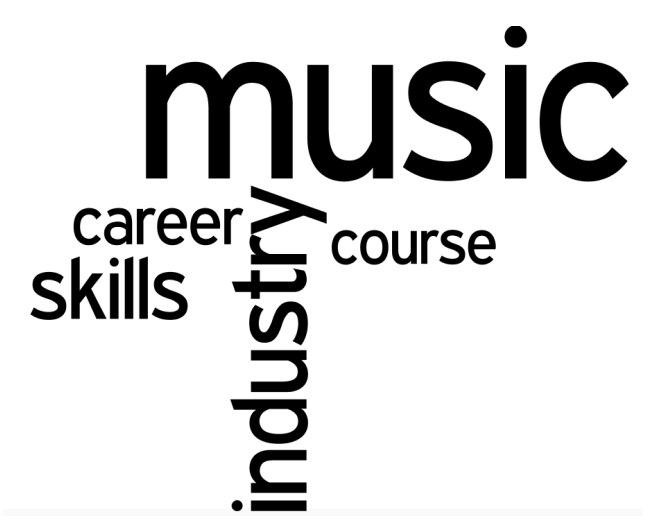

Figure 3: Overstated promotional language extracts (five-word maximum filter applied).

The image presents a stark representation of the foremost message conveyed by the extracts of some HEPs. The clear message is that undertaking study in these HEPs will lead to a career within the music industry (in the singular form). However, as has already been stated, not all HEPs were interpreted as using overstated language in their first level web based promotional materials. In such cases, HEPs tended to promote their degree programmes in a more factually descriptive manner. Extracting the text from those providers HEPs the following word cloud image:

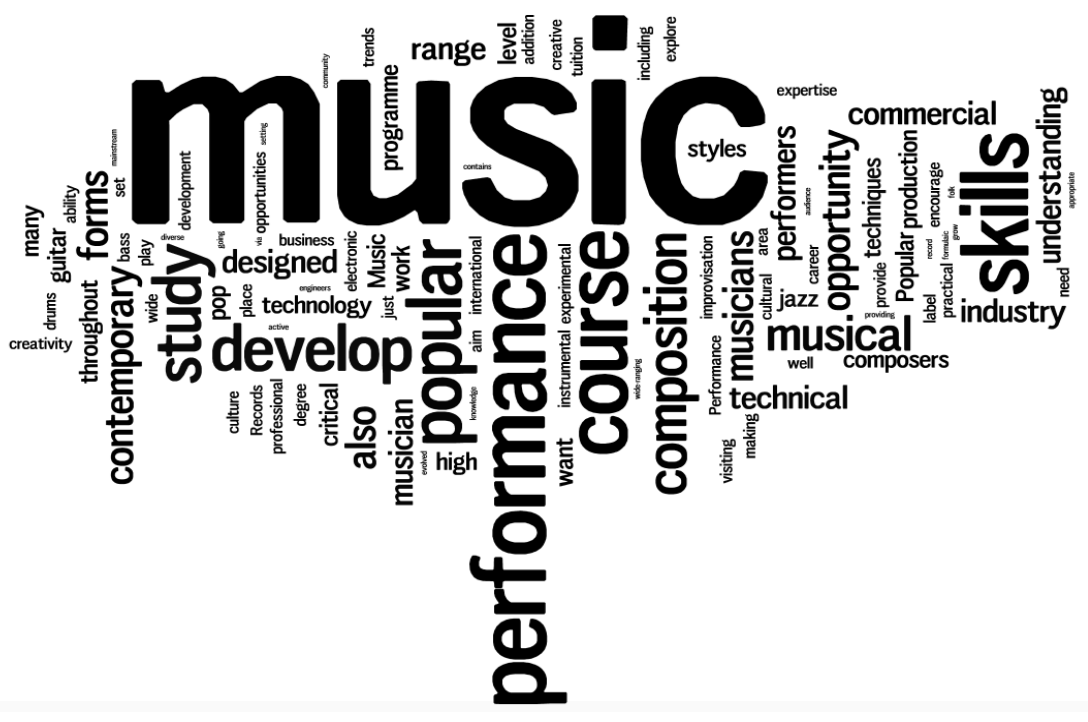

Figure 4: Understated promotional language extracts (100-word maximum filter applied). 
Again, by applying a more severe five-word filter the key focus can be observed as follows:

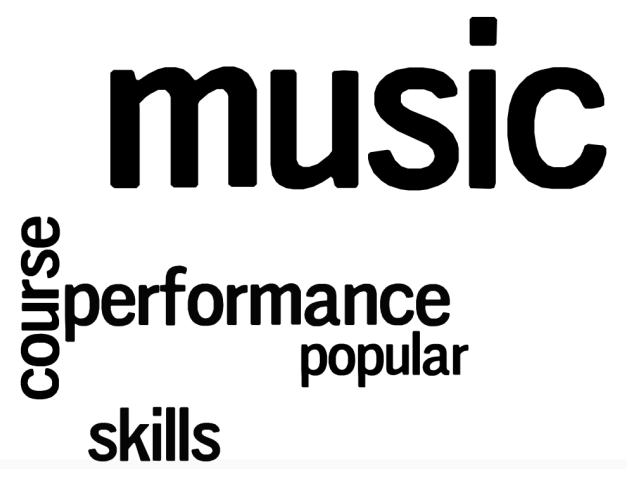

Figure 5: Understated language promotional language extracts (five-word maximum filter applied).

There is clearly a more varied and balanced approach here, with the main emphases being music and performance. On reading these excerpts it is apparent that no suggestion of a guaranteed career path from study is being made. Yet, however factually accurate and balanced these examples may be, it is questionable whether they would be particularly appealing or attractive to potential students.

\section{Discussion}

\section{Promotional strategies of a marketized sector}

Providers of higher education have a legal and moral responsibility to provide accurate information to existing and potential students (or customers). More than two-thirds of the HEPs offering HMPE degrees could be regarded as utilizzing overstated language with which to promote programmes to students. There are clear assertions in the promotional materials that studying on a particular degree will place a student in a strong position to be able to establish a long and successful career as a popular musician. Such claims, if they remain unsubstantiated, could be regarded as misrepresentation, perhaps even mis-selling. If indeed it could be argued that such examples of public information are inaccurate, then such would be an infringement of the QAA quality code to which all UK HEPs are expected to adhere. These findings support suggestions from within the wider literature of a marketization of higher education. Furthermore, they may be regarded as providing evidence for accusations of misrepresentation and disingenuousness with how HEPs convey concepts of professional careers to potential students.

Analysis of the promotional excerpts highlighted two types of approach that could be categorized as 1) a 'sales pitch' and 2) a 'factual description' approach. To an extent, the 'sales pitch approach', which uses overstated and persuasive language, is inevitable within a sector which is becoming increasingly marketized. As HEPs increasingly have to operate as businesses, HEPs have to compete for students and use promotional strategies to attract students over and above degree courses from other HEPs. Much of the language and phraseology in use within the 'sales pitch approach' implies a sense of urgency and alludes to degree courses affording greater levels of student agency. Furthermore, there is little acknowledgement of the presence of any limiting structures, and so students are left with a 
false impression of the nature of the PMI, and the extent to which student agency can be realised.

\section{Conceptual semantics}

Promotional literature for creative arts-based degrees needs to reflect the dynamic and creative environment within which they operate. Furthermore, it is expected that individuals exploring such degrees will be creative and will be expecting a certain level of interest and excitement to be found within the degree programme. It is only fair to expect a popular music degree to be couched in differing terms than for example, a degree in accountancy. Individuals will likely be looking for different linguistic cues and be motivated by different indicative content.

Whether accurate or not, the promotional literature using overstated language did make degrees sound exciting and full of potential. By comparison, the examples of promotional literature which were regarded as not utilizing overstated language did not appear as dynamic or exciting. They were clearly factually based, but they tended to read as rather dry. It is difficult to imagine that such examples of promotional literature would be as attractive to young creative musicians as the examples featuring overstated language.

The examples of non-overstated language tended to stem from popular music degrees with a more academic approach, therefore it is possible that HEPs tailor their promotional literature to their typical (or desired) student profile. It is perhaps reasonable to assume that individuals looking for a degree with a stronger academic focus, and who do not have aspirations for a professional performance career, are less likely to be attracted by promotional literature which suggests a clear route into working within the PMI. The use of overstated language, then, may be a phenomenon that is unique to those degrees in popular music with a specific vocational emphasis. If the strength of language used was obliged to accurately reflect the probability of a student reaching the high levels of success that many degrees appeared to suggest, then the language would have to be far less definitive. Ultimately, the question is whether it is possible to promote HPME degrees in a way that is engaging for potential students, but that does not utilize overstated language and make use of blurred semantics to promise outcomes the course may not be able to deliver.

Language has the power to engender particular forms of understanding (Sewell 1992), therefore what is being discussed here is an issue of conceptual semantics. The various examples of promotional literature utilising overstated language present reductive and simplified linear notions of the PMI and professional careers therein. This can arguably influence students to think about popular music careers, and popular music study, in terms of thinking of the music industry as a singular entity which operates as a meritocracy. With this logic, it is easy to presume that if an individual chooses to study, that individual will succeed, because success is a product of knowledge and skills. Ultimately, when considering the vocational value of HE, HEPs could be held to account for the realization or not of the implied promises in their promotional literature.

In reality, the content of promotional literature, whilst undoubtedly important in helping students choose a degree, is likely to be quickly forgotten once a degree programmme is commenced; at this point students have a wealth of new information with which to grapple. This subsequent information, such as course guides and programme specifications, will tend to be written in far more academic and regulatory language. Furthermore, in some cases, HEPs will be far more candid with their students about the reality of careers within the industries, 
once the students are recruited. Whilst this is an understandable approach, there is arguably a 'bait and switch' dynamic at play, if HEPs promote one understanding of the music industries and careers in promotional literature, and then a very different one post-enrolment.

\section{Concluding thoughts}

\section{The artifice of choice: information asymmetry}

Students are expected to exercise consumer choice in selecting a HEP within which to study, based on an assessment of quality and preparation for a future career. For the market mechanism to function correctly, students must exhibit the capacity to make informed decisions based on a transparency of information. White (2015: 94) raises the problem of information asymmetry between producers (the universities) and the consumers (the students) - the university having access to more or better information than the student. He suggests that even if an 'estimate of utility' were possible by a student 'she may still struggle to grasp whether that higher education was what she needed before she began to study' (White 2015: 96).

Information asymmetry is problematic because it is antithetical to democratic concepts of critical pedagogy, which pitches the HEP, teacher, and student as having equal voice. The presence of information asymmetry, therefore, is disruptive to student agency because the inequality of informational access means individuals may be making a key life-decision based on inadequate information or even falsehood. Where the existence of information asymmetry prevails, then, the true value of HPME will be difficult to comprehend.

\section{Correcting the imbalance}

Given the current climate in which HE finds itself, it is imperative that academic teams take the time to review and critically reflect upon the promotional literature for popular music degree programmes. Avoidance of reductive, suggestive or otherwise semantically obfuscated terminology is necessary both in order to help prospective students make more informed decisions as well as avoiding falling foul of any $\mathrm{CMA}^{1}$ or OfS (office for students) rulings around the mis-selling of courses ${ }^{2}$. I suggest that further study is conducted on a longitudinal basis into the career trajectories of HPME graduates from a variety of UK geographical locations. The narrative of such collective experiences would more thoroughly inform the debate concerning the efficacy of HPME degrees and the reality of careers in the PMI.

\footnotetext{
${ }^{1}$ Which? (2016) Update: universities must be compliant with consumer law. Available at: https://conversation.which.co.uk/money/cma-uni-university-higher-education-course-law (Accessed: 14/03/2019).

${ }^{2}$ The Guardian (2017) Six UK universities break advertising rules with pitches to students. Available at: https://www.theguardian.com/education/2017/nov/15/six-uk-universities-break-advertising-rules-withpitches-to-students (Accessed: 14/03/2019).
} 


\section{References}

Bakhshi, H., Freeman, A. and Higgs, P.L., 2012. A dynamic mapping of the UK's creative industries.

Ball, L., Pollard, E. and Stanley, N., 2010. Creative graduates: creative futures. CGCF Higher Education.

Bennett, T., 2015. Learning the Music Business: Evaluating the 'Vocational Turn' in Music Industry Education. London: UK Music.

British Film Institute (2017) Employment in the film industry. UK: Research and statistics unit (Accessed: 08/01/19).

Carey, G. and Lebler, D. (2012) 'Quality, Accountability, Change'. Educating Professional Musicians in a Global Context, 31

Cloonan, M. (2005) 'What is Popular Music Studies? some Observations'. British Journal of Music Education, 78-93

DCMS, U., 1998. Creative industries mapping document.

Ford, B. (2010) What are Conservatoires for? Discourses of Purpose in the Contemporary Conservatoire

Hall, R. (2017), 'Rock on or sign on? A critical evaluation of the Popular Music degree for performers in the $U K$ ', Ph.D thesis, Coventry: Coventry University

HESA (2013) HE Students by Subject area and Level of Study 2011/12. UK: Higher Education Statistics Agency

HESA (1996) Qualifications obtained at UK HE Institutions by Level of Qualification obtained, Location of Institution and Subject Area 1994/95. UK: Higher Education Statistics Agency

HESA (2019) Destination of leavers from higher education 2016/17. UK: Higher Education Statistics Agency

Hewison, R. (2014) Cultural Capital: The Rise and Fall of Creative Britain.: Verso Books

Hughes, D., Evans, M., Morrow, G., and Keith, S. (2016) 'Popular Music Education'. in The New Music Industries. ed. by Anon: Springer, 97-116

John, P. and Fanghanel, J. (2015) Dimensions of Marketisation in Higher Education.: Routledge

McGuigan, J. (2010) 'Creative Labour, Cultural Work and Individualisation'. International Journal of Cultural Policy 16 (3), 323-335 
Menger, P. 'Chapter 22 Artistic Labor Markets: Contingent Work, Excess Supply and Occupational Risk Management'. in Handbook of the Economics of Art and Culture. ed. by Anon: Elsevier, 765-811

Morrish, L. and Sauntson, H. (2013) 'BBusiness-Facing Motors for Economic Development': An Appraisal Analysis of Visions and Values in the Marketised UK University'. Critical Discourse Studies 10 (1), 61-80

Parkinson, T., 2017. Dilemmas of purpose in higher popular music education: A critical portrait of an academic field. Journal of Popular Music Education, 1(2), pp.133-150.

Pells, R. (2017) 'Number of young people planning to go to university falls to lowest level in eight years', Independent, 17th August. Available at: https://www.independent.co.uk/news/education/education-news/number-of-youngpeople-planning-to-go-university-falls-lowest-level-eight-years-students-tuitiona7884901.html (Accessed: 07/01/19).

QAA (2012) Part C: Information about Higher Education Provision. UK: Quality Assurance Agency

QAA (2016) Subject benchmark statement: Music. UK: Quality Assurance Agency

Sanigar, M. A. (2013) Selling an Education. Universities as Commercial Entities: A CorpusBased Study of University Websites as Self-Promotion. edn. UK: The University of Leeds

Sewell Jr, W. H. (1992) 'A Theory of Structure: Duality, Agency, and Transformation'. American Journal of Sociology, 1-29

UCAS (2019) Available at: https://digital.ucas.com/search/ (Accessed: 08/01/19).

UK Music (2016) Measuring Music 2016. UK: UKMusic.org

White, M. (2015) 'Some Considerations on Higher Education as a 'post-Experience Good'. Dimensions of Marketisation in Higher Education, 93

Williamson, J. and Cloonan, M. (2007) 'Rethinking the Music Industry'. Popular Music 26 (2), 305-322 